Zauret Kabylbekova Międzynarodowy Uniwersytet SILKWAY, Shymkent, Kazachstan Международный Университет SILKWAY

г. Шымкент, Казахстан

\title{
ОСОБЕННОСТИ ПЕДАГОГИЧЕСКОГО УПРАВЛЕНИЯ СИСТЕМОЙ ФОРМИРОВАНИЯ ЭТНИЧЕСКОЙ ТОЛЕРАНТНОСТИ ШКОЛЬНИКОВ
}

\begin{abstract}
Аннотация
На современном этапе развития общества, в эпоху взаимопроникновения этнокультур важной задачей воспитания становится не только формирование коммуникативной толерантности, культуры межнационального общения, но и более конкретное направление - воспитание этнической толерантности. Изучение теоретических и практических аспектов формирования этнической толерантности у учащихся общеобразовательных школ диктует необходимость целенаправленной работы с педагогами, которые непосредственно занимаются учебно-воспитательной работой с детьми в учебном процессе и во внеурочное время

Материалы и методы. Исследованы педагогические взгляды и практический опыт педагогов разных лет. Применялись тесты на владение собой, методика оценки самоконтроля в общении, анкетирование участников образовательного процесса для установления уровня управления формированием этнической толерантности школьников.

Результаты исследования. Поскольку результаты диагностической работы показали, что педагоги недостаточно конкретно нацелены на серьезную, систематичную работу по формированию этнической толерантности школьников, то нами предложены соответствующие воспитательные технологии.

Реализация задач деятельности педагога по формированию этнической толерантности у учащихся требует системных знаний и направленности самого учителя.
\end{abstract}


Ключевые слова: толерантность, этническая толерантность, процесс воспитания, формирование этнической толерантности, ценностные ориентации.

Казахстан - страна многонациональная, этнически многообразная, поэтому на первый план выдвигается потребность в формировании у подрастающего поколения целостной картины окружающего мира, духовных, культурных, нравственных ценностей в их национальном и общечеловеческом понимании.

Воспитание в духе толерантности, прежде всего, решает задачу раскрытия смысла бытия человека в мире через сквозь призму характера и способов его взаимодействия с этим миром. В конечном счете, речь идет о восприятии толерантности как личностно-значимой ценности. Обществом остро востребованы личности, способные проявить готовность к принятию и сотрудничеству, терпимость к инакомыслию, осмыслению уникальности единства и многообразия культур. Все это не может оставаться без внимания науки и обусловливает всплеск теоретических и прикладных исследований по проблемам толерантности в наши дни. Воспитание личности, обладающей толерантностью, является одной из важнейших социально - педагогических проблем.

Квинтэссенция личностно-ориентированной педагогики - становление человека личностью, способной самостоятельно действовать, принимать решения, выбирать образ существования, осознавать свой неповторимый жизненный путь и составляет специфическую цель образовательного процесса, а опыт исполнения этих функций предполагает определенное содержание и технологию образовательной деятельности.

Базовыми для данной научной проблемы являются исследования 3.Т. Абетова, А.Г. Асмолова, О.С.Анисимова, Н.М. Борытко, С.Н. Глазачева, Ж.Ж. Картбаевой, Н.М. Кудинова, А.Е. Шабалдас, Цепковой И.Б., Г.Н. Волкова и др.

Современная образовательная политика Казахстана в области этнических отношений и проблема формирования национальной модели образования в философско-социальных аспектах рассматривались в работах А.Кодар, К.Е. Кушербаева, Ж.Ж. Молдабекова, К. Нарибаева, Ж.Ж. Наурызбая, А.Н. Нысанбаева, Ш.М. Мухтаровой, Н.В. Романовой, М.М. Сужиковой др.

Большое значение для сопоставительно-сравнительного анализа в аспекте рассматриваемой проблемы имеют труды ученых ближнего и дальнего зарубежья (И.В. Балицкая, Н. Беккер, Л.В. Волосович, О.К. Гаганова, А.Н. Джуринский, 3.А. Малькова, К.Д. Салимова, М.Г. Тайчинов, М. Федулло, О.В. Чернова, О.Б. Скрябина, 3.В. Сикевич, Цао Ян, В.И. Юдин и др.).

Процесс воспитания и обучения протекает на личностном уровне и актуализирует личностные функции школьника в том случае, когда учебная де- 
ятельность и связанная с ней сфера общения приобретают значимость для дальнейшей самореализации и самоопределения. Приоритетными становятся мотивация и жизненные цели учащегося, развиваются те качества его личности, которые нужны для продвижения к цели поставленной самим школьником. Сочетание биологических особенностей организма, индивидуальной биографии, среды, общего уровня развития, направленности личности и, наконец, противоречивость ролевой структуры делают каждую личность уникальной $[1,2,3,4]$.

На современном этапе развития общества, в эпоху взаимопроникновения этнокультур важной задачей воспитания становится не только формирование коммуникативной толерантности, культуры межнационального общения, но и более конкретное направление - воспитание этнической толерантности.

В аспекте рассматриваемой проблемы определенный интерес вызывают гуманистические педагогические идеи П.Ф. Каптерева.

Подлинно научная педагогика, полагал П.Ф.Каптерев, не может быть «служанкой государственно-политической системы, а выступает как защитница интересов человека». В этом социальная функция данной сферы науки и практики. «...Есть разница во взглядах на образование, государственном и педагогическом. Заботясь об образовании, государство имеет в виду граждан определенного государства, а педагогика - прежде всего граждан мира, т.е. людей и их общее гуманитарное развитие. Педагогическое дело есть дело совести, разностороннего духовного обогащения личности, а государство следит и может следить лишь за внешним порядком...»,- отмечал ученый [5].

Подобных взглядов придерживается и ряд других педагогов. Так, В.Д. Шадриков полагает, что одной из задач, стоящих перед образованием является воспитание личности с неидеологизированным мышлением, то есть личности конструктивно мыслящей, личности, допускающей множественность истин и считающей это естественным явлением, личности, которая уважает позицию другого, личности терпимой, нравственной [6].

Е.В. Бондаревская также делает акцент на нравственную сторону воспитания толерантности, под которой они понимают социокультурную толерантность. Структурными компонентами социокультурной толерантности являются следующие качества: уважение, симпатия, эмпатия, т.е. «триада толерантности». При этом культура понимается Е.В. Бондаревской как совокупность всех жизненных отношений и форм деятельности людей, воплощая в себе интересы, цели, субъектные смыслы, ценностные ориентации, духовный потенциал и реальные возможности народа и отдельного человека [7].

Разделяя данную точку зрения, мы хотим заметить, что, учитывая важность теоретических и практических основ педагогической науки, не менее важно введение позитивных, этнотолерантных, образовательных традиций в практику на основе установления баланса и принципов диалектического 
единства общечеловеческого и этнического аспектов построения процесса воспитания школьника.

В результате изучения теоретических и практических аспектов формирования этнической толерантности у учащихся общеобразовательных школ, была выявлена необходимость конкретной целенаправленной работы со взрослыми. Целью нашего исследования было выявление психологических характеристик этнической толерантности взрослых людей из категории тех, кто непосредственно занимается учебно-воспитательным процессом учащихся в школе и во внеурочное время. В школьном возрасте для детей мнение взрослых имеет неоспоримый авторитет, поэтому самим взрослым, прямо или косвенно вовлеченным в процесс воспитания и обучения детей, нужно иметь определенные знания, представление в аспекте изучаемых этнотолерантных качеств личности и адекватное поведение для реализации поставленных целей и задач.

К данной опытно-экпериментальной работе нами были привлечены учителя общеобразовательных школ, руководители кружков по интересам и спортивных секций, а также родители учащихся школ, всего 75 человек.

При проведении работ с данной целевой группой участников эксперимента, нами были поставлены следующие задачи:

- определить степень уравновешенности и раздражительности, способность к саморегулированию процессов возбуждения и торможения у взрослых;

- определить уровень коммуникативного контроля (низкий, средний, высокий);

- провести анкетирование взрослых с целью выявления их потребностей в

изучении этнокультурных образовательных процессов (культура родного и государственного языка, знание национальной и мировой культуры и др.).

В качестве диагностического инструментария нами были использованы следующие методики: тест «Умеете ли Вы владеть собой?», тест на оценку самоконтроля в общении (по Марион Снайдер), анкета для учителей школ (по методике Ж.Ж. Наурызбая).

Теоретический анализ психолого-педагогической литературы, метод наблюдения, обобщенный педагогический опыт, а также личный опыт работы автора в образовательной системе (в школе, в педагогическом колледже, в университете) показывает, что для эффективной образовательно-воспитательной работы с учащимися в целом, и процесса формирования этнической толерантности школьника, в частности, важное значение отводится эмоционально-чувственной сфере личности учителя: его психическому состоянию и здоровью, адекватному восприятию явлений окружающей действительности, умению принимать верные решения, анализировать свои поступки и регламентировать поведение учащихся.

Общеизвестен постулат о том, что школьник, особенно в начальных класcax, часто видит и воспринимает мир сквозь призму видения и мировоззре- 
ние учителя. Учитель, равно как и многие взрослые, связанные по роду деятельности со школьником, имеет на учащегося большое влияние, поэтому мы решили вывить (выявить) уровень уравновешенности взрослых респондентов, используя методику «Умеете ли Вы владеть собой?». Ответы испытуемых распределились следующим образом. Респонденты, ответы которых отражают нормальный уровень уравновешенности - составляет 34,5\%. 33,6\% респондентов показали удовлетворительный уровень уравновешенности и участники эксперимента, показатели которых оказались ниже нормы $32 \%$. (рисунок 1).

По методике, выявляющей оценку самоконтроля в общении, респонденты показали следующие результаты: взрослые с высоким уровнем коммуникативного контроля составляют $33,6 \%$. Учителя и родители, составившие данную группу, являются примером коммуникативности, правильно выстраивают линию общения с детьми школьного возраста, вникают в волнующую проблему, могут дать дельный совет, к которому ребенок прислушается.

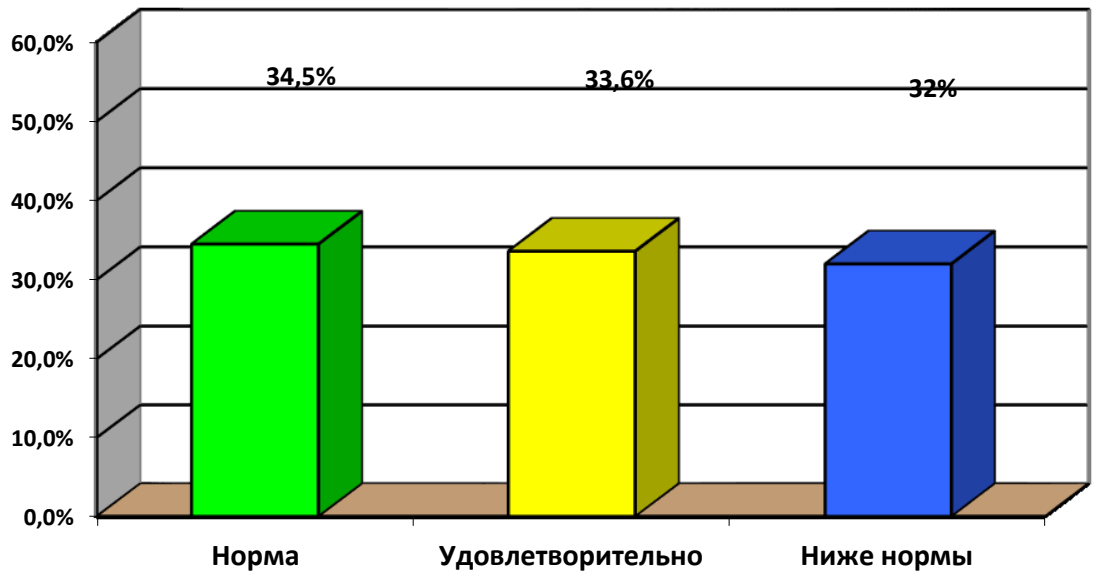

Рисунок 1. - Результаты диагностики уровня уравновешенности взрослых респондентов

Следует отметить, что у детей-подростков в переходном возрасте часто возникают проблемы с общением: с учителями, родителями, сверстниками и он нуждается в советах компетентных взрослых. 34,5\% составляют участники эксперимента со средним уровнем коммуникативного контроля и $32 \%$ составили респонденты с низким уровнем коммуникативного контроля (рисунок 2 ). 


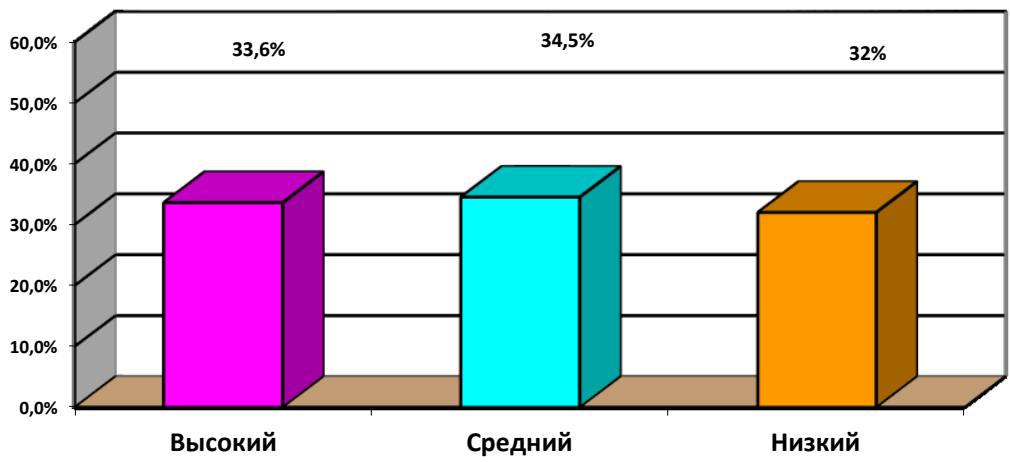

Рисунок 2. - Результаты диагностики самоконтроля в общении взрослых респондентов

Анкета для учителей школ, воспитателей, руководителей кружков, спортивных секций и родителей состоит из пяти групп ответов, направленных на формирование толерантности. Так, по результатам ответов на вопрос: «Должен ли человек овладеть мировой культурой или достаточно знать культуру своего народа?», ответы распределились следующим образом: ответы на вопрос: «Должен овладеть» составляют 33,6\%; ответы на вопрос: «Достаточно своей культуры» составляют 29,4\%; «не знаю»- составляют $37 \%$.

Ответы по результатам на вопрос: «Считаете ли Вы, что знание родного и государственного языков, а также изучение иностранного языка содействует развитию личности?» распределились следующим образом: «да» - составляют $36,1 \%$; «частично»- составляют 20,2\%; ответы - «нет»- составляют $12,6 \%$; «не знаю»- 31,1\%. В целом, респонденты признают необходимость изучения языков по разным причинам, приведем наиболее часто встречающие мотивы к изучению языков: «пригодится в будущем», «если сын (дочь) пожелает учиться за границей», «чтобы найти престижную работу в иностранной организации», «для общего развития» и др.

Ответы по результатам на вопрос: «Что дает школа Вашим детям?» распределились следующим образом: те, кто считает, что школа обеспечивает общие знания - составляет 48\%; возможность выбрать профессию - составляет 4,2\%; умение жить в обществе - составляет 7,6\%; знание истории, языка и культуры своего народа - 3,4\%; знание мировой культуры- составляет 1,7\%; «ничего не дает»- составляет $3,4 \%$; «затрудняюсь ответить» - составляет 32\%. (Рисунок 3). 


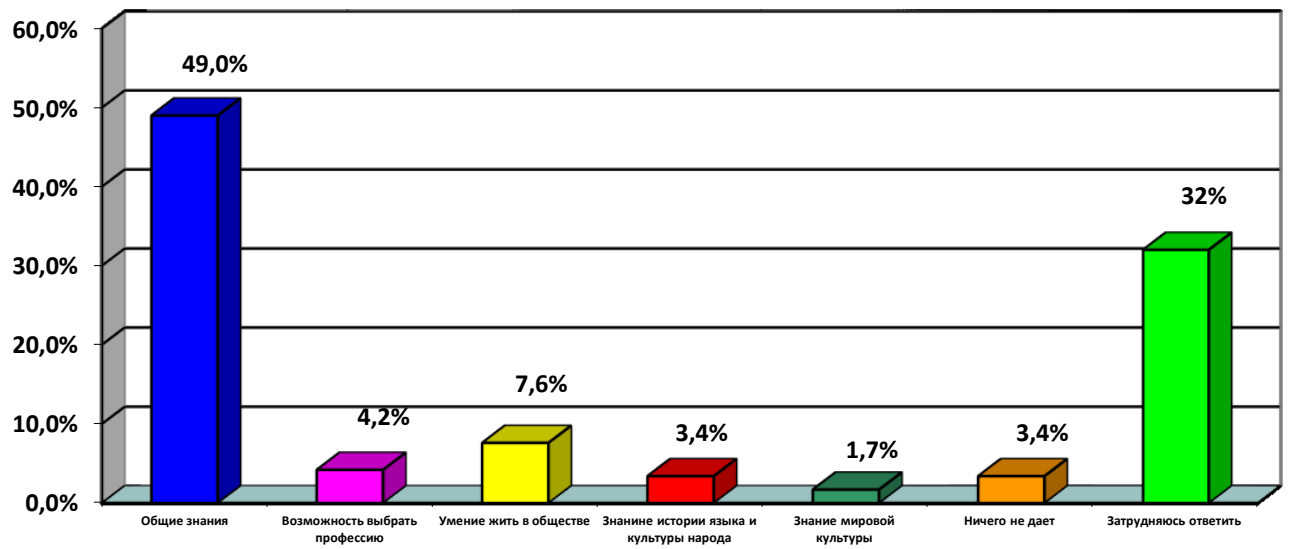

Рисунок 3.- Результаты анкетирования взрослых, направленных на формирование толерантности.

По итогам ответов на данный вопрос, а также последующей беседы с респонентами было выявлено, что многие взрослые считают, что современная школа в основном, ограничивается обеспечением школьников необходимыми базовыми знаниями. Отдельными респондентами было высказано такое мнение, что более глубокие знания (для успешного участия в едином национальном тестировании (ЕНТ) при поступлении в ВУЗ и т.д.) их детям дают дополнительные курсы вне школы, занятия с репетиторами. 32\% респондентов признались, что никогда не задумывались об этом, поскольку общеобразовательная школа в их сознании ассоциируется с очередной, обязательной ступенью в развитии человека, а содержание образования и воспитания должно регулироваться государственными стандартами, без учета мнения родителей.

Лишь 4,2\% респондентов связывают возможность выбрать профессию с обучением в школе. Многие родители полагаются в этом вопросе на свое мнение по принципу: «Я - отец (мать) и мне виднее будущее моего ребенка», на личные способности школьника, на мнение руководителей спортивных секций, творческих кружков. На наш взгляд, в этом плане положительное влияние может оказать профориентационная работа среди учащихся школ не только в выпускных классах, а гораздо раньше, возможно в среднем звене обучения; активная работа школьных психологов по определению интересов школьника к той или иной профессии и др.

В связи с тем, что в процессе обучения и воспитания подрастающего поколения организующая и координирующая роль отводится учителю, а конкретнее, классному руководителю, мы провели анкетирование среди педагогов школь с иелью установления уровня организации работы по формиро- 
Особенности педагогического управления системой формирования...

ванию этнической толерантности икольников. Результаты анкетирования классных руководителей представлены в нижеследующей таблице.

Состояние воспитательной работы по формированию этнической толерантности школьников

\begin{tabular}{|c|c|c|c|}
\hline \multirow[t]{2}{*}{ № } & \multirow{2}{*}{ Вопросы для классных руководителей } & \multicolumn{2}{|c|}{$\begin{array}{l}\text { Результатьл } \\
\text { ответов в \% }\end{array}$} \\
\hline & & Да & $\mathrm{Hem}$ \\
\hline 1 & $\begin{array}{l}\text { Приобщение школьников к национальным и общечеловеческим } \\
\text { ценностям происходит под воздействием: } \\
\text { - учителей } \\
\text {-родителей } \\
\text {-одноклассников (сверстников) } \\
\text {-информации, получаемой из СМИ, Интернет,ТВ }\end{array}$ & $\begin{array}{l}84 \\
51 \\
18 \\
35\end{array}$ & $\begin{array}{l}26 \\
49 \\
82 \\
65\end{array}$ \\
\hline 2 & $\begin{array}{l}\text { Проводите ли Вы воспитательную работу по формированию } \\
\text { этнической толерантности школьников }\end{array}$ & 72 & 28 \\
\hline 3 & $\begin{array}{l}\text { Какие мероприятия, связанные с вопросами формирования } \\
\text { этнической толерантности школьников вами проведены? } \\
\text { - классные часы; } \\
\text {-диспуты, дебаты, круглый стол; } \\
\text {-экскурсии в национальные культурные центры; } \\
\text {-конкурсы по ФЭТШ; } \\
\text { - тренинг, беседы, лекции; } \\
\text {-другие виды работ (укажите какие) }\end{array}$ & $\begin{array}{c}37 \\
29 \\
5 \\
4 \\
20 \\
5\end{array}$ & \\
\hline 4 & $\begin{array}{l}\text { Принимают ли участие родители учащихся в мероприятиях по } \\
\text { формированию этнической толерантности? }\end{array}$ & 30 & 70 \\
\hline 5 & $\begin{array}{l}\text { Считаете ли Вы необходимым в учебно-воспитательном } \\
\text { процессе изучение культур разных народов: } \\
\text { - казахского; } \\
\text { - других культур }\end{array}$ & $\begin{array}{l}65 \\
45\end{array}$ & $\begin{array}{l}35 \\
55\end{array}$ \\
\hline 6 & $\begin{array}{l}\text { От чего, на ваш взгляд, зависит эффективность работыл } \\
\text { классного руководителя по формированию этнической } \\
\text { толерантности школьников? } \\
\text { - организация кружков по изучению культуры народов; } \\
\text { - личный пример педагогов; } \\
\text { - привлечение родителей к работе с детьми; } \\
\text {-увеличение информации об истории, культуре, национальных } \\
\text { традициях народов на уроках и классных часах; } \\
\text { - проведения групповых и массовых форм работы (конкурсы, } \\
\text { фестиваль, олимпиада, экскурсии и др.) }\end{array}$ & $\begin{array}{l}21 \\
16 \\
30 \\
21 \\
12\end{array}$ & \\
\hline
\end{tabular}


Результаты анкетирования позволяют сделать вывод о том, что учителя школ в цуелом проводят определенную воспитательную работу по формированию этнической толерантности. Так, большинство учителей $-84 \%$ (в основном, это классные руководители и учителя начальных классов) ведут со школьниками внеклассную воспитательную работу, направленную на соблюдение норм и правил толерантного общения, на взаимоуважение между детьми разных национальностей, на изучение традиций и обычаев разных этносов.

В то же время, в ходе бесед выяснилось, что по сравнению с учителями начальных классов, классные руководители классов среднего звена школы считают, что родители в большей степени ответственны за толерантное поведение детей.

Лишь 72\% классных руководителей проводят воспитательную работу по отдельным аспектам этнической толерантности, 30 \% привлекают к совместной работе родителей. 12 \% считают проведение групповых и массовых форм работы (конкурсы, фестиваль, олимпиада, экскурсии и др.) наиболее эффективными. Информачию, получаемой из СМИ, недостаточной для формирования толерантности считают 35 \% респондентов. Прослеживается недостататочная связь с культурными центрами, хотя в нашем городе функционирует Ассамблея народов Казахстана, включающая множество диаспор. В то же время классньле руководители активно поддержали необходимость их учения истории, культуры, национальных традиций различных народов на уроках и классных часах.

Результаты диагностической работы показали, что учителя школ, воспитатели, руководители кружков, спортивных секций и родители учащихся недостаточно конкретно представляют себе всю серьезность работы по формированию этнической толерантности. Также было выявлено, что подобная работа ведется стихийно, по мере возникновения сложных ситуаций и проблем. Более того, многие учителя в учебно-воспитательном процессе не всегда считают нужным уделять внимание толерантным качествам, поскольку на уроках важно работать на усвоение обязательного учебного материала, а время на воспитательные моменты не планируется.

Изученные и проанализированные нами планы воспитательной работы классных руководителей среднего звена общеобразовательных школ г. Шымкента почти не содержат мероприятий, направленных на формирование толерантных качеств личности школьника. Многие ограничиваются лишь участием в массовых мероприятиях, проводимых в общешкольном и городском масштабе, таких, как «Наурыз», «Масленица», «День солидарности народов Казахстана», «День города», «День независимости РК» и др. Некоторые учителя и родители признались, что сами не знакомы с содержанием слов «то- 
лерантность» и «этническая толерантность», и эти слова не включены в их активный словарный запас.

Изучение реального состояния исследуемой проблемы, позволяет нам сделать следующие выводы:

1. Диагностика существующего состояния знаний учащихся об этнической культуре народов в ходе экспериментального исследования показала определенный процент низкого и среднего уровня, недостаточного для формирования этнической толерантности школьника. В то же время опросы учащихся и учителей, анализ содержания образовательно-воспитательных мероприятий показывают, что они обладают большим потенциалом в формировании этнической толерантности школьника.

2. Большинство опрошенных школьников имеют определенное представление об этнической толерантности, определяют его некоторые аспекты. В то же время, обращает внимание наличие низкого уровня знаний народного опыта, традиций, обычаев в области толерантных отношений.

3. В настоящее время в школе подготовка педагогического коллектива по формированию у учащихся этнической толерантности организована на недостаточном уровне. В воспитательной работе используются однообразные формы, не создающие мотивацию учащихся к самообразованию и личностному развитию. Малоэффективны внеклассные и внешкольные мероприятия, проводимые без учета индивидуального и возрастного развития детей школьного возраста, без учета степени сплочения классного коллектива, его возможностей для проявления инициативы и активности, включения учащихся в разнообразные виды деятельности, адекватные аспектам формирования этнической толерантности у учащихся общеобразовательных школ.

С учетом всего вышеизложенного, нами был разработан план и программа элективного спецкурса «Формирование толерантной личности школьников в современных условиях». При разработке данного программного материала, мы исходили из следующих целей и задач.

Цель спецкурса - расширение и углубление теоретической подготовки и повышения квалификации учителей образовательных школ, их подготовка к воспитанию толерантной личности школьника, организации образовательного пространства на толерантной основе, развитию толерантного сознания и установок толерантного отношения к различным субъектам педагогической реальности.

Задачи курса:

1. Способствовать воспитанию толерантной личности, способного адаптироваться к условиям полиэтнического общества, подлинного носителя этнокультурных и общечеловеческих ценностей. 
2. Ознакомить будущих и действующих специалистов педагогического профиля с базовыми понятиями и критериями толерантности.

3. Формировать духовно - нравственные, патриотические потребности студентов, учителей, родителей и слушателей курсов повышения квалификации учителей.

4. Расширить круг умений и навыков работы с научной, педагогической, историко-философской литературы путем применения различных методов мыслительной деятельности (анализ, сравнение, обобщение и классификация, наблюдения и др.)

5. Приобщение слушателей курсов повышения квалификации учителей к изучению и познанию родного языка, литературы, истории как источников возрождения этнического самосознания и основы толерантного отношения к явлениям окружающей действительности.

Предполагаемые результаты - повышение уровня педагогического управления процессом формирования этнической толерантности школьников.

Программа элективного спецкурса, рассчитанная на 26 академических часов, рекомендуется учителям, студентам педагогических специальностей, родителям, слушателям курсов повышения квалификации. Программа предполагает проведение интегрированных занятий, логически взаимосвязанных по содержанию и поделенных на 2 блока. Первый блок - теоретическая часть, включающий изучение основ толерантности. Второй блок отводится проведению практических занятий, в рамках которых предполагаются разнообразные виды работ (посещение национальных культурных центров, областного музея, творческая коллективная деятельность учащихся, дебаты, фестивали, тренинги, исследование культурных и образовательных потребностей школьника с применением методов анкетирования, бесед, опроса и др.), способствующие развитию и воспитанию толерантных качеств личности детей школьного возраста.

Программа спецкурса была апробирована в 2017-2018 году в ряде школ города Шымкента (в школе № 26, № 9), в настоящее время ведется подготовка к внедрению программы для студентов нашего университета.

Таким образом, результаты проведенного нами исследования свидетельствуют о том, что реализация задач деятельности педагога по организации процесса формирования этнической толерантности подрастающего поколения требует системных знаний и направленности самого учителя. Систематическая целенаправленная учебно-воспитательная работа вооружает учащихся знаниями, являясь, на наш взгляд, основным звеном по формированию этнотолерантных качеств. 


\title{
Список использованных источников
}

Омаргазин Р.Б. Сущность духовности: монография. - Астана: ЕНУ, 2006. $328 \mathrm{c}$.

Кабылбекова З.Б. Теоретико-методологические основы формирования этнической толерантности у учащихся общеобразовательных школ. - Дисс... .д.п.н. - Шымкент: ЮКГУ им.М.Ауезова, 2010. - 355 с.

Гумерова Р.Б., Кутушева Р.Р., Алгушаева В.Р., Хухрин М.С. Исследования этнической толерантности у рабочей молодежи . Уфы / Р.Б. Гумерова// Международный научно-исследовательский журнал. - 2016. Выпуск: № 10 (52) Часть 4. С. 115-120.

Попова Е. В. Предпосылки и условия формирования толерантности личности на разных возрастных этапах // Научно-методический электронный журнал «Концепт». 2015. № 3 (март). С. 76-80.

Каптерев П.Ф. История русской педагогики // Педагогика. - 1996. - № 2. - С. 68-72.

Шадриков В.Д. Философия образования и образовательные политики. - М.: Исследовательский центр проблем качества подготовки специалистов, 1993. - $181 \mathrm{c}$.

Бондаревская Е.В. Смысль и стратегии личностно-ориентированного воспитания // Педагогика. - 2001. - № 1. - С.17-24.

\section{Pedagogical management of the system of shaping ethnic tolerance of school children}

\begin{abstract}
The article concerns the problem of pedagogical management of the students ethnic tolerance system. It was noted that at the current stage of society development, in the age of interpenetration of ethnocultures, an important task of education is not only shaping communication tolerance, culture of interethnic communication, but also the education of ethnic tolerance. The article presents the results of the study, the purpose of which was to determine the basic features of ethnic tolerance of adults in the category of people directly involved in the educational process of students at school and after school hours. It has been shown that teachers are not particularly focused on serious, systematic work on shaping the ethnic tolerance of school children, so the implementation of the teachers tasks in organizing the process of forming ethnic tolerance of the young generation requires system knowledge and orientation of the teacher himself.
\end{abstract}


Keywords: tolerance, ethnic tolerance, education process, formation of ethnic tolerance, axiological orientations

\section{Specyfika pedagogicznego zarządzania systemem formowania tolerancji etnicznej wśród uczniów}

\section{Streszczenie}

Artykuł dotyczy problemu zarządzania pedagogicznego systemem tolerancji etnicznejuczniów.Zwróconouwagę, że na obecnym etapie rozwoju społeczeństwa, w epoce przenikania się etnokultur, ważnym zadaniem edukacji jest nie tylko kształtowanie tolerancji komunikacyjnej, kultury komunikacji międzyetnicznej, ale także wychowanie tolerancji etnicznej. W artykule przedstawiono wyniki badania, celem którego było określenie podstawowych cech tolerancji etnicznej dorosłych z kategorii osób bezpośrednio zaangażowanych w proces edukacyjny uczniów w szkole i po godzinach szkolnych. Ukazano, że nauczyciele nie są specjalnie ukierunkowani na poważną, systematyczną pracę nad kształtowaniem tolerancji etnicznej dzieci w wieku szkolnym, więc realizacja zadań nauczyciela w organizowaniu procesu formowania tolerancji etnicznej młodego pokolenia wymaga wiedzy systemowej i orientacji samego nauczyciela.

Słowa kluczowe: tolerancja, tolerancja etniczna, proces edukacji, formowanie tolerancji etnicznej, aksjologiczne orientacje. 